\title{
"Maybe we can work together" : Researchers' outcome expectations for sharing knowledge on social media
}

\author{
Hussain Alshahrani ${ }^{\mathrm{a}}$ \& Diane Pennington ${ }^{\mathrm{b}}$ \\ ${ }^{a}$ Department of Computer and Information Sciences, University of Strathclyde, Glasgow, UK \\ and Shaqra University, Shaqra, Saudi Arabia \\ ${ }^{b}$ Department of Computer and Information Sciences, University of Strathclyde, Glasgow, UK
}

This is a peer reviewed, accepted author manuscript of the following in press research article: Alshahrani, H., \& Pennington, D. (Accepted/In press - 07 Sept. 2020). "Maybe we can work together": Researchers' outcome expectations for sharing knowledge on social media . Global Knowledge, Memory and Communication. 


\section{"Maybe we can work together": Researchers' outcome expectations for sharing knowledge on social media}

Purpose: To investigate the outcomes that researchers expect from using social media for knowledge sharing and to explore how these outcomes impact their use.

Design/methodology/approach: The authors conducted 30 semi-structured interviews with researchers at a major Scottish university. They analysed the interview transcripts using directed content analysis.

Findings: Researchers expect social and personal outcomes from the use of social media to share knowledge. Each type has positive and negative forms. The positive outcomes motivate researchers to use it, whereas negative outcomes prevent them from using it.

Research limitations/implications: This study extends the integrative theoretical framework of outcome expectations within social cognitive theory by exploring these outcomes and their relative amount of influence on sharing ideas, experiences, questions, and research outputs on social media. While the participants included academic staff and postdoctoral researchers, the majority were PhD students.

Practical implications: The findings will help individual researchers and universities employ social media effectively in sharing ideas and promoting research through identifying the positive outcomes. Identifying the negative outcomes will help in employing solutions to overcome them.

Originality/value: This is the first known study to investigate the outcome expectations that impact researchers' use of social media for knowledge sharing.

Keywords: outcome expectations, social media, knowledge sharing, researchers, academics, social cognitive theory

\section{Introduction}

People increasingly use social media to communicate and share knowledge. Facebook, Twitter, LinkedIn, YouTube, and other platforms allow people to share ideas, pictures, comments, and other forms of knowledge (Kaplan and Haenlein, 2010). Researchers can easily share knowledge with others to improve their own ideas, or to help others to develop theirs (Panahi et al., 2016a). Their use can avoid constraints that occur within traditional sharing methods. It also enables researchers to share multimedia content (Fotis, 2015).

For example, through social media, researchers can learn what was discussed at conferences without physically attending. In addition, it is used as a channel for researchers to present themselves and their work to others in the same area (Veletsianos, 2016). Moreover, it can provide an effective way for researchers to engage and interact with communities (Carrigan, 2016). They can reach other researchers using social media to share their knowledge (Ellison et al., 2015). Knowledge in this study refers to cognitive experiences that researchers earned from their continuing study (tacit), or that have been articulated in documents as research outputs (explicit). Indeed, by using this tool, researchers can share what they have learnt and practiced in their work as well as what they have produced as written communication. 
Several studies focus on the use of social media for knowledge sharing and the factors that affect it (e.g. Bilgihan et al., 2016, Cheung et al., 2013, Cho et al., 2010, Eid and Al-Jabri, 2016, Kwahk and Park, 2016, Ma et al., 2014, Oh and Syn, 2015, Al-Jabri, 2020, Franchi \& Tomaiuolo, 2020) but it still needs more investigation (Edwards et al., 2017, Panahi et al., 2012b, Razmerita et al., 2014). According to prior work (e.g. Cheung et al., 2013, Cho et al., 2010, Kwahk and Park, 2016, Vuori and Okkonen, 2012), reputation, enjoyment, reciprocity, social interaction, learning, and rewards can be significant influences. These factors may represent expected outcomes. An outcome expectation is "a judgment of the likely consequence such behaviour will produce" (Bandura, 1986, p. 391). Outcome expectations are operationalised in this study as the positive and negative outcomes that researchers expect from the use of social media as a channel for knowledge sharing. While it is known that they expect potential outcomes from using it, there are not adequate studies to understand what they are. This study addresses this gap through the following research questions:

RQ1: What outcomes do researchers expect from the use of social media for knowledge sharing?

RQ2: How do these outcome expectations impact the use of social media for knowledge sharing?

\section{Literature Review}

\subsection{Outcome Expectations}

Outcome expectations is one of the two important factors in social cognitive theory (Bandura, 1986, p. 391). The outcome relates to the consequence of the act, not the act itself. Occasionally, outcome expectations are misconstrued and considered to be the effectiveness of a technique; however, the technique is not an outcome itself, but rather a means for producing an outcome (Bandura, 1986).

According to the theory of personality (Rotter, 1966), outcomes are determined either by an individual's action or by external factors beyond an individual's control. Therefore, individuals who believe that their outcomes are determined by their actions and behaviours tend to be more active compared with those who perceive events more fatalistically (Bandura, 1986). The belief in personal determination of outcomes creates a feeling of efficacy and power, whereas the belief that outcomes occurs based on what an individual does results in apathy (Bandura, 1986). Rotter argued that the relation is between actions and outcomes rather than with personal efficacy (Rotter, 1966). In contrast, Bandura (1986) argued, “outcomes determined by one's own actions can be either demoralizing or heartening, depending on the level of self-judged efficacy" (p. 413).

Bandura (2004), categorised outcome expectations into three types. The first type is physical, which refers to pleasurable or aversive effects of the behaviour for benefits or losses. The second type is social, or what the behaviour produces in an individual's interpersonal relationships. The final type is self-evaluative or self-satisfaction, which can be positive or negative, and refers to the reactions to an individual's behaviour and status. Shoffner et al. (2005) classified outcome expectations into five types; three of these were from Bandura (2004). The two new types were generativity and relational outcome expectations. Generativity outcome expectations include the impact of personal success, potential creation and discovering, and altruistic motivation. Relational outcome expectations include interpersonal and social impact. Some overlap between these forms exists, especially between generativity and self-satisfaction, and between relational and social outcome expectations.

Hsu et al. (2007) discussed knowledge sharing behaviour within virtual communities of professional societies. They identified two kinds of outcome expectations: personal and community-related. Personal outcome expectations refer to the expectations of individuals 
such as making friends or getting a better return, whereas community-related outcome expectations refer to the individuals' belief about the impact of their knowledge sharing. They concluded that personal outcome expectations have a significant influence on knowledge sharing behaviour, but community-related outcome expectations do not.

Compeau et al. (1999) highlighted two types of outcomes expectations from individuals' benefits that were derived from their actions. Likewise, numerous studies have provided empirical support for individuals' benefits (e.g. reward, enjoyment) which can motivate knowledge sharing (Bock and Kim, 2001, Bock et al., 2005, Kankanhalli et al., 2005). If researchers who use social media believe that they may receive extrinsic benefits such as promotion, educational enrichment, a new position, or monetary rewards from their knowledge sharing, they will have a more positive attitude toward knowledge sharing (Hsu et al., 2007).

\subsection{Knowledge Sharing}

Knowledge sharing is a vital research topic currently. It has been defined in various ways such as knowledge exchange with others (Chow and Chan, 2008, Connelly and Kelloway, 2003), transfer or dissemination of knowledge between individuals, groups or organisations (Bukowitz and Williams, 2000, Lee, 2001), and exchanging experience, thought, or understanding (Sohail and Daud, 2009). According to Alshahrani and Pennington (2018), "knowledge sharing is defiened as a process of interactions through which knowledge is exchanged between individuals, groups and organisations. This interactive exchange occurs through the use of social media, which is highly interactive (p. 1277). The current study operationalises knowledge sharing as making experiences and research outputs available on social media.

Knowledge sharing can help individuals improve their learning and understanding by gaining new knowledge, and therefore performing their work more effectively (Brown et al., 2013). According to Ramayah et al. (2013), knowledge sharing among researchers takes four forms: publishing books or articles, formal interactions such as workshops, informal interactions, and interacting with communities. They can earn potential benefits from sharing, such as acquiring rewards or improving performance. Srivastava et al. (2006) argued that "knowledge sharing may lead to better team performance for at least two reasons: improved decision making, and coordination" (p.1242).

Organisations share knowledge to achieve competitive advantage (Liebowitz, 2001) and organisational success (Sohail and Daud, 2009). Indeed, knowledge sharing can enhance organisational effectiveness and performance, especially in knowledge-based organisations such as universities (Al-Hawamdeh, 2003, Gupta and Govindarajan, 2000, Olivera, 2000, Petrash, 1996). They realise that knowledge sharing amongst people contributes to the achievement of competitive advantage (Gaál et al., 2015). When employees share knowledge within their organisations, the quality of work and efficiency improves (Brown et al., 2013). Social media is perhaps the newest way to share knowledge. Panahi (2014) studied the ways in which social media can facilitate tacit knowledge sharing by conducting semi-structured interviews with 24 physicians; he found 21 different ways. Other previously referenced studies investigated these factors (e.g. Cheung et al., 2013, Cho et al., 2010, Kwahk and Park, 2016, Al-Jabri, 2020).

\subsection{Researchers' Use of Social Media}

As previously stated, 'researchers' in this study refers to those who contribute to knowledge and conduct research (Nassuora and Hasan, 2010). Researchers' primary role is knowledge creation and dissemination, and they are considered as the best example of those who practice sharing knowledge (Jolaee et al., 2014, Alshahrani \& Rasmussen Pennington, 2018, 2019). For example, according to Veletsianos (2016), researchers use Twitter to enhance their knowledge 
and skills in their fields by requesting resources or explanations about ideas that could be used in their research or lectures. Therefore, it is useful to explore how they share knowledge with others and what channels they use.

There are important motivations or benefits for researchers to use social media, including disseminating their research, increasing their citation counts, and gaining visibility within their research communities. This can be achieved by using any social platform (Carrigan, 2016).

Some social media platforms are for academics only, such as Academia.edu and ResearchGate, both of which allow researchers to archive and categorise their papers and make them available for others to share (Carrigan, 2016). Researchers can also seek assistance from others on these sites by asking questions (Veletsianos, 2016). They are also used to announce new publications (Carrigan, 2016).

On social media, people from different research areas can interact and exchange experience, inspire ideas, and build communities (Veletsianos, 2017). Moreover, researchers can use it to develop new theories and learning models, discuss with experts, and obtain constructive criticism and feedback (Jabr, 2011). Researchers may gain potential outcomes from the use of social media, though there are not adequate studies to understand these outcomes and how they impact knowledge sharing.

\section{Methodology}

According to Armstrong and Franklin (2008), universities are one of the most important places for producing and sharing knowledge. Therefore, this study uses a specific university, the University of Strathclyde in Glasgow, Scotland, as its setting. Strathclyde is the third largest university in Scotland (Darby, 2017). It has four Faculties: Engineering, Science, Business, and Humanities \& Social Sciences. The university researchers' use of social media is not as effective as it could be, despite institutional encouragement toward sharing research outputs and academic accomplishments (G. Macgregor, personal communication, August 2017).

The authors recruited participants by posting flyers around the university. The inclusion criteria were academics, researchers, and $\mathrm{PhD}$ students at the University of Strathclyde who claimed to use social media for sharing and discussing professional knowledge and outputs.

\subsection{Data Collection}

The data were collected through 30 semi-structured interviews, with participants representing all four Faculties. The authors used convenience sampling, a non-probability and non-random sampling strategy (Etikan et al., 2016). They recruited based on researchers' availability to participate and the ease of communication (Etikan et al., 2016) due to proximity. The sample included six academic staff, one research assistant, and $23 \mathrm{PhD}$ students.

They designed the interview guide using the theoretical lens of social cognitive theory (Bandura, 1986, 1989), which encompasses outcome expectations. It was discussed and pilot tested with academic colleagues and then revised accordingly. The final interview guide can be found in Appendix A. However, there are two additional questions $(12,13)$, which were developed in case that if any of the participants does not use social media in general or for knowledge sharing particularly. Indeed, these two questions have not been used since all the participants use social media for sharing knowledge. They received ethical approval from the Departmental Ethics Committee in the University of Strathclyde's Department of Computer and Information Sciences.

In the interview, one author first introduced the nature and purpose of the study to the participants, and then obtained informed consent. The interviewer commenced by requesting standard demographics. Then, the participants were asked open-ended questions in relation to their outcome expectations about the use of social media for sharing knowledge, and the impact of these outcomes. The interviewer never used the term "outcome expectations" in order to 
avoid uncertainty or confusion. Instead, the interviewer used familiar phrases such as "reasons," "benefits," "advantages," and "disadvantages". Each interview was conducted at a time and place convenient for the participant. The average interview time was about 30 minutes. All interviews were audio recorded after receiving permission. All recordings were professionally transcribed and then imported into NVivo 11 for analysis.

\subsection{Data analysis}

The authors analysed the transcripts with directed content analysis. Content analysis is defined as "the intellectual process of categorizing qualitative textual data into clusters of similar entities, or conceptual categories, to identify consistent patterns and relationships between variables or themes" (Julien, 2008, p. 120). These themes may emerge from the analysis of the transcripts, or might be identified a priori and the researchers simply seek evidence for these themes.

According to Elo and Kyngäs (2008), there are three stages to conduct content analysis: preparation, organisation, and reporting. In the preparation stage, researchers started with transcribing all 30 audio recordings by using a professional transcription service. The researchers read the transcripts and listened to the audio recordings for interviews at the same time to verify the accuracy of the transcripts. Then, they selected the unit of analysis, which was a theme. In the organising stage, the researcher created main themes with sub-themes and codes, and then grouped these codes under the suitable themes and sub-themes. The codes were derived from theory and research findings (Hsieh and Shannon, 2005). Indeed, the codes were derived from the idea introduced by Bandura $(1998,2004)$ which classified outcome expectations into three types: physical, social, and self-satisfaction. In the final stage, the researcher reported the analysing process and the results by categorising the data under these main themes and their sub-themes. The researchers used rich and detailed descriptions to convey the findings in order to make them more realistic (Creswell, 2014).

Hsieh and Shannon (2005) outlined three approaches to qualitative content analysis: conventional, directed, and summative. Since the authors attempted to extend the theoretical framework of outcome expectations (Bandura, 1986, 1989), they used directed content analysis as it is the appropriate approach to extend a theoretical framework: "codes are defined before and during data analysis, and derived from theory or relevant research findings" (Hsieh and Shannon, 2005, p. 1286).

In order to ensure consistency and accuracy, the authors read the transcripts and listened to the audio recordings for interviews at the same time. They also read and reflected on the transcripts several times after coding to make sure that codes had not shifted in meaning or definition during the process (Gibbs, 2008). The researchers also asked senior colleagues who were not familiar with the study to provide an objective assessment, such as the relationship between the research questions and the data, the level of analysis, and the interpretation (Creswell, 2014).

\section{Findings}

\subsection{Use of Social Media}

The participants used different social media platforms to share knowledge. The most common platform used by the participants was Twitter, which was used by $70 \%$ of 30 participants. The second most common was Facebook with $60 \%$, followed by LinkedIn and ResearchGate with $43 \%$ and $40 \%$ respectively. Other platforms were represented, but they were less used, as shown in Figure 1. 
(Figure 1 about here)

\subsection{Outcome Expectations}

The authors classified outcome expectations into two overarching types: social and personal. Each type took positive and negative forms. A set of sub-themes emerged within each form (Table 1).

\section{(Table 1 about here)}

\subsubsection{Social Outcome Expectations}

Social outcome expectations are the social consequences that occur from using social media for knowledge sharing with communities. These outcomes can be positive (e.g. attracting people, networking, social impact, and visibility) which represent the social benefits, or negative (e.g. lack of trust) which represents social disadvantages.

\section{- Positive Social Outcomes}

Attracting people is defined as drawing people's attention toward researchers' work through social media. This was one of the most commonly observed social outcomes. The first purpose was to lead others to read about their research.

I think it is the easiest way to attract other people to read what you are doing. Not just read what you are doing but know what you are doing. (3)

For sharing, I suppose it is an ego thing. You want more people to read your material.... I have had a lot of people read material from the non-academic community and I would not have had that without Twitter. (11)

I always hope that people will read what I put out there. (14)

The second was to find an audience for their knowledge and experience. New researchers in particular may have difficulties in cultivating an audience that is interested in their field without using social media.

I think it is a bit of about feeling that you have an audience. Because if you are stuck in the lab seven hours a day or something, I think part of you also wants to show the world that "yes, I am working really hard". That kind of thing. (15)

I think the main reason is to reach the right audience. If I share my experience in normal social media or in the old way, then it becomes really difficult for me to reach my targeted audience, the ones who are interested or who share this interest with me. (22)

I think that's the most convenient way to find other academics and access a very broad audience. (2)

The third purpose was to recruit research participants; social media may enhance or replace traditional recruitment methods. 
I will get the opportunity to find and recruit people to help me in the process of my study. (3)

It is around the recruitment of participants. .... I recruited families that I would not have been able to before, would not have had access to. (5)

The fourth purpose was to exchange ideas and experiences with others quickly and easily.

It's quite useful for me to get ideas out there, because it's a way of almost processing your own thinking. (18)

I think it could be a good kick-starter of future academic career this one because once you get started like that, it's easier to exchange ideas with other people and it saves you a ton of time because you don't have to spend that much time looking. (2)

Networking is defined as interacting with others to build relationships and research communities that encourage exchanging knowledge; it is foundational for knowledge sharing. Many participants acknowledged social media's essential role in building personal relationships and networks, thereby growing their research communities in their own disciplines and other disciplines.

For me the more positive impact of it has been the growth of my research community. (11)

I do think it creates a network of people involved in research. (17)

If you could use social media as a better, more efficient through way of networking to other professionals then I suppose that would be a good reason to use it. (13)

To get network and know people who are interested in the UK, that should help me in terms of citations and in terms of making connections and in terms of seeing what people are doing and what their major area is. (28)

I think it is a very handy platform for you to find more people who are likeminded in their research interest for building networks. (29)

It is building those new relationships. (12)

So I find social media, for me, is a really good way to make social ties with people. (14)

Engagement was an important aspect of building relationships through networking, which is essential because the research environment thrives on engaging with others. Social media allows researchers to connect with a wide range of people that might not otherwise be reached.

I will try to talk to people, just a kind of engagement. (6)

It is great to help meet people, find what other people are doing, and engage with them on that level. (10)

I guess in traditional forms of research, you might be looking at a very limited group of views, in a sense. Whether they are academic, or journals, or specific, but there is an opportunity here to engage with a whole new group of people. Ideas, whether they're in the UK or abroad, or elsewhere. Different ages, different sectors, different levels of education. There's a real opportunity there, I think, to engage. (18) 
Collaboration is also an important aspect of networking. According to the participants, the use of social media is the most successful way to meet people and collaborate. Using social media to share their research could lead to collaboration opportunities.

I was already getting messages from different companies saying, "Okay, we've viewed your profile. Maybe you'd be interested in collaboration, there is this research project or maybe you would like to do an internship." (2)

It might help me in the future in case a professor or lecturer reads my work and sends me an email and says, "Do you want us to collaborate?" Maybe if I finish doing what I'm doing and produce an actual thing, maybe a company will go online and see what I'm doing and say, "I want to buy this." I don't know. (3)

Then people are aware of your portfolio, so they might then access your web profile and see your other interest areas, because you're only tweeting that one paper. But your profile network would then evolve, and it may lead to new collaborations. (5)

I can contact these people who are in the same interest very easily. Maybe we can work together, to collaborate on a certain area. (26)

Social impact is how social media reaches and ultimately impacts relevant people and communities. Researchers use it to share their experience within their own institutions or from others.

\begin{abstract}
We keep producing knowledge or producing comments, this knowledge for me at least is not a goal in itself, the goal is to make an impact. By delivering that knowledge or those recommendations to the right people, the likelihood for this impact to happen be higher I would say. (22)

You need to be getting involved in these forms of communication, because I think there is an expectation more widely for universities to have impact. (18)

When Twitter came, I used it, and I found this had more impact, and would affect all the community, so I should stick with it. That is what happened. (23)
\end{abstract}

As Participant 18 noted, universities are vital places for creating, developing, and sharing knowledge. University researchers' knowledge can achieve wider impact in multiple communities through sharing on social media.

Visibility refers to what extent social media helps researchers to become known in their fields and communities. This is a key factor, especially for younger researchers who want to be noticed, work with others, and share their work.

I think academics who are very active on social media will be more visible within the younger set of their field.... Yes, I think especially amongst younger researchers any academic who is active on social media is more visible and potentially that might have an impact on their citation rates. (12)

The first outcome will be increasing my visibility as a new player to the field. (2)

I'm aware that really, technically, if you engage in Research Gate and academia.edu and all these things for people who seemingly have a whole day a month minimum to sit and do all this- I know that if you do that, I think it should help to build up more, not even citations in academic terms, but more visibility that it should help more people see the work that you've produced, specifically because it is kind of tucked away and hidden. (6) 


\subsubsection{Personal Outcome Expectations}

Personal outcome expectations are individual consequences. These can be positive (getting help, getting feedback, publicising and citations, keeping up-to-date, and getting a job) or negative (distractions, privacy concerns, and time-consuming).

\section{- Positive Personal Outcomes}

The expected personal benefits included getting help, getting feedback, publicising and citations, keeping up-to-date, and getting a job, as explained below.

Social media can be used to get help from others. New researchers in particular want assistance from more knowledgeable researchers. Social media can help them overcome difficulties experienced in learning how to do research.

The benefit I got from social media when I had a new problem facing me, during my research, I used social media to solve this problem. (7)

It may help my thesis, [finding a new methodology]. It should help my methodology or how to choose this method and what should be the respondent and so on. (30)

The most important things that encourage me or the reason behind using social media is to learn from others. (28)

Researchers also can find papers or materials that would be difficult to obtain in other ways.

The main benefit I get from it is finding papers. (8)

So specific outcomes, it's getting journals which I don't have access to. (21)

Social media grants the opportunity to get feedback about researchers' work to help them improve it by discussing with experts - immediately, in many cases, due to the real-time nature of social media communication.

Getting feedback from people who have area expertise. (2) 
I probably have the feedback that I can get from those experts, because my content is delivered to experts who know the material and therefore they can critically evaluate my work. I think the advantage of having this platform is to receive that feedback. (22)

I expect that people read what I share and they give me feedback, that "It's good, it's useful, for my research for my trip or whatever" and I want some comments and advice. (30)

The obvious things are getting likes, retweets, comments. So, it's immediate feedback. (12)

Publicising and citing are essential for researchers. There have always been various ways to do this, but social media is a newly effective way to distribute outputs, thereby encouraging others to use and cite them in their own work. This can lead to increased citation counts and improved notoriety in their own institutions.

I would guess to publicise their own work. (8)

I think you want to get your work out there when you're doing research. (17)

The goal of being an academic. It's about sharing the knowledge and getting credit for what you're doing. More or less, that's how we are judged. We are judged by the research output. If you produce a paper and you get 2000 citations in a year that means that you've done something good. (3)

Trying to get my citation count up. Probably the citation count, which is now more important in academia I think.... More views of my articles, more downloads of my articles. (16)

If a paper is promoted beforehand, before you have started your research, maybe you will go to that paper first. It gives you more of a chance to be cited, the opportunity to be cited by other people. (26)

Keeping up-to-date is another positive social outcome. Knowledge travels and changes faster now than ever, and the ability to keep up is essential. Participants said that social media helps them keep up-to-date about what others are doing and what is new in their field.

I think I tend more to keep up to date with what people are doing in a more general sense. (14)

Maybe at one time I will work with my colleagues via the social media. After graduation, we do have the alumni. This will also keep me up to date with my university, with the research there. (23)

The first reason is to know what the newer things, to be on time. (28)

I think otherwise it would be very difficult to keep other people up-to-date. (2)

As previously stated, social media can increase researchers' visibility and increase their reputation. This may lead them to getting a job.

The long term is that someone might read about my work and be interested in what I am doing, or the way I have approached it, and maybe get a job. (3)

It may get you into a job somewhere. (25) 
I was hoping it would be quite good for job prospects, thinking if I put up a few pieces, I think my written English is pretty decent, so I thought this would show that I know what I am talking about. If I did have a potential recruiter or employer that stumbled across my profile, and then they saw not only has he got a profile with his history here, but he is also actively talking about what he is interested in as well, I thought it would be quite good from that point of view for just demonstrating that I am not passive in my research. I am actually showing interest beyond that, and that I know what I am talking about from the get go. That was a main benefit. (27)

\section{- Negative Personal Outcomes}

Negative personal outcomes refer to the disadvantages that researchers expect from the use of social media for knowledge sharing. According to the study participants, there are three expected disadvantages: distractions, privacy concerns, and time-consuming.

Participants believed that distractions could prevent them from concentrating on important work by becoming overly preoccupied with less important things.

If there is no thinking or you are not so careful, it can also lead to distractions. (1) I think there's distraction issue. I think that's an issue. I think ensuring the quality of your work retains, high, it's not misinterpreted. (18)

Privacy concerns relate to keeping personal matters and relationships as well as research data separate from the public. Social media may affect privacy in way or another, and privacy was identified as important to the participants.

It's all about exposure and data privacy. So, everyone knows you shouldn't post things about confidential research that you're doing. (13)

Privacy, I think. (16)

Privacy concerns about social media in general hold me back from using it more than I would otherwise, and more openly than I currently do. (10)

Time-consuming was the participants' key concern. Different social media platforms have their own features that could be beneficial for researchers; however, the fear is about how much time it will take to use them as well as consuming knowledge that is irrelevant, not useful, or not credible.

It wastes your time. (1)

I suppose some of the disadvantages are the time it can take and if you're using lots of different platforms, to keep them all up to date at the same time. (5)

It can be a total time suck is the main disadvantage. (12)

For me the disadvantage is that it takes time. It takes a lot of my time. (26)

The fact that if you spend too much time on it, then it's a hindrance to your work. (29)

There is the waste of time aspect, where you're not just getting academic information, you're getting all kinds of things, but some of the information from academic sources are also not useful. (14)

\section{Discussion}




\subsection{Types of Outcome Expectations}

\subsubsection{Social Outcome Expectations}

Social outcome expectations are the social consequences of using social media for knowledge sharing with communities. Based on the findings, this study identified two forms of social outcomes: positive and negative. On the positive side, four important positive social outcomes were found: attracting people, networking, social impact, and visibility. These outcomes have also been found by other studies as significant factors that motivate researchers to use these social platforms to share their experience and research outputs (e.g. Al-Taee, 2014; Gaál et al., 2015; Gibbs et al., 2013; Jarrahi, 2013; Kimmerle, Moskaliuk, Oeberst, \& Cress, 2015; Okazaki, Andreu, \& Campo, 2017; Oostervink et al., 2016; van Winkelen \& McKenzie, 2011; Yu et al., 2010).

The current study confirmed that researchers attract people by using social media for several purposes. These purposes include presenting their work, finding their audience, exchanging ideas, and recruiting participants for their studies. This aligns with the findings of previous studies (e.g. Donelan, 2016; Elsayed, 2016; Greifeneder et al., 2018).

Greifeneder et al. (2018) reported that researchers use social media to attract and check new staff members. Caers and Castelyns (2011) and Nández and Borrego (2013) argued that researchers use it for recruitment.

The findings of the present study are also consistent with other studies that support networking as another important outcome of the use of social media for sharing knowledge. Researchers are interested in building relationships with other researchers or colleagues through any social media platform; this is for a number of reasons. They use it to collaborate, engage, and extend their research community. This is in agreement with the findings of Greifeneder et al. (2018), who argued that researchers maintain profiles on social media to create new networks and find new collaborations. It is also consistent with Oh and Syn (2015), who reported that engagement is one of the main factors that motivate people to use social media.

The current study confirmed that researchers use social media to share their experience and their work in order to see the social impact of these experiences and this work. This impact might be achieved by delivering experience and research outputs to those who benefit from them through these social platforms. This aligns with previous studies such as Carrigan (2016), Veletsianos (2016), and Kietzmann, Hermkens, McCarthy, and Silvestre (2011). For instance, Kietzmann et al. (2011) stated, "Yet others see social media as a way of making their message heard and positively impacting humanitarian causes, environmental problems, economic issues, or political debates" (p. 244).

Another positive social outcome was visibility. The findings of the present study also confirmed that researchers desire to increase their visibility in their communities by using this tool. This is consistent with Oostervink et al. (2016), Gibbs et al. (2013), Leonardi, Huysman, and Steinfield (2013), and Treem and Leonardi (2012), which argued that social media afford users the ability to make their knowledge, experience, and work visible to others.

Indeed, social media enable researchers to add information, experiences, achievements, work, and any other details. This is a basic feature of this tool, which leads researchers to be seen and recognized by others and vice versa (Treem \& Leonardi, 2012). Thus, researchers can see what other researchers do and learn from them, or increase their reputation among those researchers (Leonardi et al., 2013). Greifeneder et al. (2018) stated that researchers desire to display their skills in an effective way rather than using traditional means such as a CV or a list of publications.

As shown in previous paragraphs of this section, four main positive outcomes are represented among social outcome expectations. Researchers use social media for sharing cognitive experience and research outputs in order to obtain these social outcomes. 
However, this type of outcome, as stated before, has a negative side. According to the findings of this study, only one outcome represented negative social outcomes, namely the lack of trust. Indeed, researchers are anxious about their ideas and work that has not yet been published, lest these be used somewhere else without citation or permission. As is known, social media provide a channel for the public who desire to communicate, participate, and interact. Thus, it could be difficult to counteract some negative behaviours such as plagiarism. This leads to lack of trust on the part of researchers as regards using this tool for knowledge sharing. This argument is in alignment with a number of studies (e.g. Bilgihan et al., 2016; Kwahk \& Park, 2016; Papadopoulos et al., 2013; Yu et al., 2010a).

Some studies have confirmed that the weakness of social media use was due to lack of trust (e.g. Abrizah et al., 2014; Coppock \& Davis, 2013; Greifeneder et al., 2018). Thus, it can be argued that this negative outcome has a significant effect on researchers' use of social media to share knowledge.

\subsubsection{Personal Outcome Expectations}

Personal outcome expectations are the personal consequences to researchers of the use of social media for knowledge sharing. With regard to this type, the findings of this study found that researchers use social media to get a number of benefits that can improve their experience, ideas, careers, and even lives. The important positive personal outcomes that researchers expect from using this tool are getting help, getting feedback, publicity and citation, keeping up-todate, and getting a job. This is in agreement with other studies (e.g. Jarrahi, 2013; Majchrzak, Faraj, Kane, \& Azad, 2013; Oostervink et al., 2016; Panahi, 2014; Panahi et al., 2012a, 2012b; Pi et al., 2013; Yu et al., 2010), whose arguments confirmed that these benefits can enhance the use of social media to share knowledge.

Social media can help researchers obtain what they need. For example, in some cases, researchers are in strong need of finding an expert on a specific issue. One of the best ways to locate this expert is to use social media (Panahi, 2014). This tool can be a way of getting help with solving problems (Pi et al., 2013), helping others to solve their problems (Yu, Lu, \& Liu, 2010a), helping others to achieve their objectives (Pi et al., 2013), or finding any other form of help (Oh \& Syn, 2015).

Any work needs to be evaluated and given some feedback to improve it. Social media have become the most effective means of communicating with those who have experience and obtaining their feedback. Therefore, researchers utilize these media to do so in order to develop their work (Gibbs et al., 2013; Leonardi et al., 2013; Pi et al., 2013; Van Noorden, 2014).

Researchers attempt to find the best way to publish their work, experience, ideas, and thoughts and share them with others. According to the findings of this study and previous studies, social media constitute the best tool for distributing these outputs and letting others find and cite them in their own work (Al-Taee, 2014; Gaál et al., 2015; Panahi, 2014). This can enable researchers to increase their credit by letting others see, read, cite, and interact with their research outputs and experience. This is also what their institutions aim to achieve.

According to the results of this study and of previous studies such as Aifan (2015), Al-Taee (2014), Panahi (2014), Panahi, Watson, and Partridge (2016b), and Yuan, Zhao, Liao, and Chi (2013), researchers use social media to keep them up-to-date with their research fields. Thus, this is another important benefit that is expected from using this tool for sharing knowledge. For example, Panahi et al. (2016b) argued that keeping up-to-date is an important challenge facing physicians in their profession. This challenge can be met by using social media.

As discussed earlier in regard to these media and their role in promoting researchers' visibility in their communities, this tool may in one way or another lead them, particularly new researchers, to get a job somewhere. This was found by the current study and is in agreement 
with a number of other studies (e.g. Caers \& Castelyns, 2011; Greifeneder et al., 2018; Nández $\&$ Borrego, 2013), which confirmed that this tool is one of the best methods of job seeking. Indeed, there are some social platforms used by researchers specifically to present their research outputs, such as ResearchGate and LinkedIn. In these platforms, the researchers mention their research and professional interests. From time to time, they receive job offers that fit those interests. Therefore, this tool is one of the best ways to get the desired job.

The negative side of personal outcome expectations from researchers' use of social media that was found in the current study can be summarized as containing three important disadvantages. The first one was distraction. In fact, this is one of the key disadvantages of the use of social media, inasmuch as this tool takes researchers away from their duties and work. This point is consistent with Aifan (2015), Coppock and Davis (2013), Gibbs et al. (2013) and Greifeneder et al. (2018). Researchers leave their tasks and duties to deal with this tool and this in turn may affect their achievement and performance in other areas. This negative outcome was expected from the use of this tool.

The second disadvantage was impairment of privacy. Privacy is the main concern behind the weakness or non-use of any social technology. The results of the current study and previous studies such as Jarrahi (2013); Madhusudhan (2012); Panahi (2014) confirmed this point. When researchers use social media professionally and personally, they think that it may threaten their privacy to some extent, as their personal matters (e.g. family issues) may become known to their colleagues and vice versa. Thus, this is another negative outcome expected from the use of this tool.

Researchers may use social media for several hours a day and this can lead to wastage of time. Thus, time consumption is another negative side of such use. This point was confirmed by the results of the current study. These findings agreed with the results of previous studies such as Coppock and Davis (2013); Greifeneder et al. (2018); Jamali, Nicholas, and Herman (2015), when they argued that social media can be the foremost way of wasting time. This is the third negative outcome that was expected from the use of this tool.

To conclude these points about outcome expectations, this study has contributed to the existing body of knowledge by investigating researchers' outcome expectations of the use of social media for knowledge sharing.

\subsection{The Impact of Outcome Expectations}

\subsubsection{Positive Outcome Expectations}

Social and personal positive outcomes motivate researchers to use social media. The participants stated that they might use it more if they achieve benefits. They noted this when asked about how positive outcomes might influence their use.

I probably would start using the platform more, or find myself checking out more, and maybe even start posting more frequently. (27)

I think this will increase my using for social media as well. This will increase as well not only using, but to follow people on the last things, on last studies that they are doing and the major finding. (28)

If I see these outcomes, if I'm experiencing these benefits, then I'm bound to use social media more in my future for my future projects. (29)

These benefits not only lead to increased use, but they can make this use more effective. This aligns with previous studies (e.g. Panahi et al., 2013, Yu et al., 2010b).

\subsubsection{Negative Outcome Expectations}


Social and personal negative outcomes can prevent researchers from using social media, as participants discussed.

Privacy concerns about social media in general hold me back from using it more than I would. (10)

If I had negative experience it would push me off from the platform. (12)

If I had more negative experiences it might put me off from using it. (27)

These negative outcomes might prevent researchers from gaining potential benefits. Other studies have also found this concern (e.g. Alwagait et al., 2015, Ma and Chan, 2014).

\subsection{Implications}

This study contains several implications. From a theoretical perspective, the study further develops the theoretical framework of outcome expectations by identifying types and forms within a real-life context. In a practical sense, researchers who want to use social media more effectively should be made aware of the benefits, decide which ones are important to them, and learn to use it to achieve these benefits.

The negative outcomes are worrisome, but researchers should be made aware of how to control them in order to obtain the benefits. For example, with respect to distraction and time consumption, researchers could identify specific times during the day to use social media and restrict themselves to these times only so they do not lose focus on their important tasks or waste time. Regarding privacy concerns, researchers may use strategies to protect themselves. For example, they could use two accounts: a professional one for use during working hours, and a personal one for other uses. Finally, because researchers can use these platforms to build relationships with others, they need to learn to trust others, unless negative behaviours occur. Researchers can at the very least use social media to share their work that has already been published in pre-print or final form, because these will obviously be public regardless.

Universities can and should encourage their researchers to use social media for knowledge sharing. They could reward those who are active on desired channels because it will increase the visibility and impact of the university. They should also provide support, training, and mentorship for those who are not experienced social media users. These strategies can help researchers as well as universities develop more effective and engaging social media presences, which can assist with promoting the institution's strategic goals (Alshahrani \& Rasmussen Pennington, 2018).

\section{Conclusion}

This study investigated the outcomes that researchers expect from the use of social media for knowledge sharing, and to explore how these outcomes impact their use. The authors interviewed 30 participants about their outcome expectations. They identified two types: social and personal. Each type has positive and negative forms. The positive outcomes lead to use this tool more effectively, whereas the negative outcomes ultimately lead to inactive use or non-use entirely. The findings provide an opportunity for researchers to better understand what outcomes they can obtain from this tool and the impact of these outcomes on this use, and suggest why and how universities should support and encourage their researchers to use these platforms.

One limitation of this study is the sample. Based on convenience sampling, participants selfselected. Due to non-response from senior researchers, the majority of participants in this study were $\mathrm{PhD}$ students. Because of this, the authors could not make comparisons between the different levels of researchers. 
Future work will involve the administration of an online quantitative survey that will be informed by the findings from the interviews. The authors will aim to reach a larger, more diverse sample within the university population.

\section{References}

Abrizah, A., Badawi, F., Zoohorian-Fooladi, N., Nicholas, D., Jamali, H. R., \& Norliya, A. (2014). "What do scholarly channels and resources do authors trust to read, cite and publish in?: A Malaysian study". Paper presented at the Library: Our Story, Our Time, Our Future: Proceedings of the International 5th Conference on Libraries, Information and Society (ICoLIS) 2014, University of Malaya, Kuala Lumpur.

Aifan, H. A. (2015). "Saudi students'attitudes toward using social media to support learning". Doctor of philosophy, University of Kansas, Kansas.

Al-Hawamdeh, S. (2003), Knowledge Management: Cultivating Knowledge Professionals, Elsevier, Chandos, Oxford.

Al-Jabri, I. M. (2020). "Investigating the Mediating Role of Knowledge Sharing on Employee Engagement: Evidence from a Developing Nation". International Journal of Human Capital and Information Technology Professionals (IJHCITP), 11(1), 47-63.

Alshahrani, H., \& Rasmussen Pennington, D. (2018). “"Why not use it more?” Sources of selfefficacy in researchers' use of social media for knowledge sharing". Journal of Documentation, Vol. 74 No. 6, pp. 1274-1292.

Alshahrani, H. and Rasmussen Pennington, D. (2019), "“How to use it more?" Self-efficacy and its sources in the use of social media for knowledge sharing", Journal of Documentation, Vol. 76 No. 1, pp. 231-257.

Al-Taee, M. L. (2014). "The role of social networking tools in facilitating knowledge management and sharing processes at the UAE municipalities: opportunities and challenges". Doctor of philosophy, University of Birmingham, Birmingham.

Alwagait, E., Shahzad, B. \& Alim, S. (2015). "Impact of social media usage on students academic performance in Saudi Arabia". Computers in Human Behavior, Vol.51 (Part B), pp. 10921097.

Armstrong, J. \& Franklin, T. (2008). "A review of current and developing international practice in the use of social networking (Web 2.0) in higher education". http://franklinconsulting.co.uk/LinkedDocuments/the $\% 20$ use $\% 20$ of $\% 20$ social $\% 20$ networking $\% 20$ in $\% 20 \mathrm{H}$ E.pdf (accessed 2 August 2017).

Bandura, A. (1986), Social Foundations of Thought and Action: A Social Cognitive Theory, PrenticeHall, Englewood Cliffs, NJ.

Bandura, A. (1989), "Human agency in social cognitive theory", American Psychologist, Vol. 44 No. 9, pp. 1175-1184.

Bandura, A. (1998). "Health promotion from the perspective of social cognitive theory". Psychology and Health, Vol. 13 No. 4, pp. 623-649.

Bandura, A. (2004). "Health promotion by social cognitive means". Health Education \& Behavior, Vol. 31 No. 2, pp. 143-164.

Bilgihan, A., Barreda, A., Okumus, F. and Nusair, K. (2016), "Consumer perception of knowledgesharing in travel-related online social networks", Tourism Management, Vol. 52, pp. 287-296.

Bock, G.W. \& Kim, Y.G. (2001). "Breaking the myths of rewards: An exploratory study of attitudes about knowledge sharing". Information Resources Management Journal, Vol. 15 No. 2, pp. $14-21$.

Bock, G. W., Zmud, R. W., Kim, Y. G. \& Lee, J. N. (2005). "Behavioral intention formation in knowledge sharing: Examining the roles of extrinsic motivators, social-psychological forces, and organizational climate". MIS quarterly, Vol. 29 No. 1, pp. 87-111.

Brown, S.A., Dennis, A.R., Burley, D. and Arling, P. (2013), "Knowledge sharing and knowledge management system avoidance: the role of knowledge type and the social network in 
bypassing an organizational knowledge management system", Journal of the American Society for Information Science and Technology, Vol. 64 No. 10, pp. 2013-2023.

Bukowitz, W.R. and Williams, R.L. (2000), The Knowledge Management Fieldbook, Financial Times/Prentice Hall, London.

Caers, R., \& Castelyns, V. (2011). "LinkedIn and Facebook in Belgium: The influences and biases of social network sites in recruitment and selection procedures". Social Science Computer Review, 29(4), 437-448.

Carrigan, M. (2016), Social Media for Academics, Sage, London.

Cheung, C.M.K., Lee, M.K.O. and Lee, Z.W.Y. (2013), "Understanding the continuance intention of knowledge sharing in online communities of practice through the post-knowledge-sharing evaluation processes", Journal of the American Society for Information Science and Technology, Vol. 64 No. 7, pp. 1357-1374.

Cho, H., Chen, M. and Chung, S. (2010), "Testing an integrative theoretical model of knowledgesharing behavior in the context of wikipedia", Journal of the American Society for Information Science and Technology, Vol. 61 No. 6, pp. 1198-1212.

Chow, W.S. and Chan, L.S. (2008), "Social network, social trust and shared goals in organizational knowledge sharing", Information \& Management, Vol. 45 No. 7, pp. 458-465.

Compeau, D., Higgins, C. A. \& Huff, S. (1999). "Social cognitive theory and individual reactions to computing technology: A longitudinal study". MIS quarterly, Vol. 23 No. 2, pp. 145-158.

Connelly, C.E. and Kelloway, K.E. (2003), "Predictors of employees' perceptions of knowledge sharing cultures", Leadership \& Organization Development Journal, Vol. 24 No. 5, pp. 294301.

Coppock, E. G., \& Davis, L. (2013). "Status of the adoption of social media in the scientific research community". Information Services \& Use, 33(3-4), 203-217.

Creswell, J.W. (2014), Research Design-Qualitative, Quantitative \& Mixed methods Approaches, SAGE Publications, Thousand Oaks, CA.

Creswell, J.W. and Clark, V.L.P. (2011), Designing and Conducting Mixed Research Methods, SAGE, Thousand Oaks, CA.

Darby, H. (2017), "University financial and strategic overview", available at: www.strath.ac.uk/media/ps/humanresources/cse/staffinduction/Main_session_induction__Main_pres_Sept17.pdf (accessed 21 September 2017).

Donelan, H. (2016). "Social media for professional development and networking opportunities in academia". Journal of Further and Higher Education, 40(5), 706-729.

Edwards, D., Cheng, M., Wong, I.A., Zhang, J. and Wu, Q. (2017), "Ambassadors of knowledge sharing: co-produced travel information through tourist-local social media exchange", International Journal of Contemporary Hospitality Management, Vol. 29 No. 2, pp. 690-708.

Eid, M.I. and Al-Jabri, I.M. (2016), "Social networking, knowledge sharing, and student learning: the case of university students", Computers \& Education, Vol. 99, pp. 14-27.

Ellison, N.B., Gibbs, J.L. and Weber, M.S. (2015), "The use of enterprise social network sites for knowledge sharing in distributed organizations: the role of organizational affordances", American Behavioral Scientist, Vol. 59 No. 1, pp. 103-123.

Elo, S. and Kyngäs, H. (2008), "The qualitative content analysis process", Journal of Advanced Nursing, Vol. 62 No. 1, pp. 107-115.

Elsayed, A. M. (2016). "The use of academic social networks among Arab researchers: A survey". Social Science Computer Review, 34(3), 378-391.

Etikan, I., Musa, S.A. and Alkassim, R.S. (2016), "Comparison of convenience sampling and purposive sampling", American Journal of Theoretical and Applied Statistics, Vol. 5 No. 1, pp. $1-4$.

Fotis, J.N. (2015), "The use of social media and its impacts on consumer behaviour: the context of holiday travel", Doctor of Philosophy, Bournemouth University, Bournemouth.

Franchi, E., Poggi, A., \& Tomaiuolo, M. (2020). "Social media for online collaboration in firms and organizations". In Information Diffusion Management and Knowledge Sharing: Breakthroughs in Research and Practice (pp. 473-489). IGI Global. 
Gaál, Z., Szabó, L., Obermayer-Kovács, N. and Csepregi, A. (2015), "Exploring the role of social media in knowledge sharing", Electronic Journal of Knowledge Management, Vol. 13 No. 3, pp. 185-197.

Gibbs, G. (2008), Analysing Qualitative Data, Sage, London.

Gibbs, J. L., Rozaidi, N. A. \& Eisenberg, J. (2013). "Overcoming the "ideology of openness": Probing the affordances of social media for organizational knowledge sharing". Journal of Computer-Mediated Communication, Vol. 19 No. 1, pp. 102-120.

Greifeneder, E., Pontis, S., Blandford, A., Attalla, H., Neal, D., \& Schlebbe, K. (2018). "Researchers' attitudes towards the use of social networking sites". Journal of Documentation, 74(1), 119136.

Gupta, A.K. and Govindarajan, V. (2000), "Knowledge management's social dimension: lessons from nucor steel", MIT Sloan Management Review, Vol. 42 No. 1, pp. 71-80.

Hsieh, H.F. and Shannon, S.E. (2005), "Three approaches to qualitative content analysis", Qualitative Health Research, Vol. 15 No. 9, pp. 1277-1288.

Hsu, M.-H., Ju, T. L., Yen, C.-H. \& Chang, C.-M. (2007). "Knowledge sharing behavior in virtual communities: The relationship between trust, self-efficacy, and outcome expectations". International Journal of Human-Computer Studies, Vol. 65 No. 2, pp. 153-169.

Jabr, N.H. (2011), "Social networking as a tool for extending academic learning and communication", International Journal of Business and Social Science, Vol. 2 No. 12, pp. 93-102.

Jamali, H. R., Nicholas, D., \& Herman, E. (2015). "Scholarly reputation in the digital age and the role of emerging platforms and mechanisms". Research Evaluation, 25(1), 37-49.

Jarrahi, M. H. (2013). "Social Technologies and Informal Knowledge Sharing within and across Organizations". Doctor of Philosophy, Syracuse University, New York.

Jolaee, A., Md Nor, K., Khani, N. and Md Yusoff, R. (2014), "Factors affecting knowledge sharing intention among academic staff", International Journal of Educational Management, Vol. 28 No. 4, pp. 413-431.

Julien, H. (2008), "Content analysis", The SAGE Encyclopedia of Qualitative Research Methods, Vol. 2, pp. 120-122.

Kankanhalli, A., Tan, B. C. \& Wei, K. K. (2005). "Contributing knowledge to electronic knowledge repositories: an empirical investigation". MIS quarterly, Vol. 29 No. 1, pp. 113-143.

Kaplan, A.M. and Haenlein, M. (2010), "Users of the world, unite! The challenges and opportunities of social media", Business Horizons, Vol. 53 No. 1, pp. 59-68.

Kietzmann, J. H., Hermkens, K., McCarthy, I. P., \& Silvestre, B. S. (2011). "Social media? Get serious! Understanding the functional building blocks of social media". Business horizons, 54(3), 241-251.

Kimmerle, J., Moskaliuk, J., Oeberst, A. \& Cress, U. (2015). "Learning and collective knowledge construction with social media: A process-oriented perspective". Educational Psychologist, Vol. 50 No. 2, pp. 120-137.

Kwahk, K. Y. and Park, D. H. (2016), "The effects of network sharing on knowledge-sharing activities and job performance in enterprise social media environments", Computers in Human Behavior, Vol. 55, Part B, pp. 826-839.

Lee, J. N. (2001), "The impact of knowledge sharing, organizational capability and partnership quality on IS outsourcing success", Information \& Management, Vol. 38 No. 5, pp. 323-335.

Leonardi, P. M., Huysman, M., \& Steinfield, C. (2013). "Enterprise social media: Definition, history, and prospects for the study of social technologies in organizations". Journal of Computer-Mediated Communication, 19(1), 1-19.

Liebowitz, J. (2001), "Knowledge management and its link to artificial intelligence", Expert Systems with Applications, Vol. 20 No. 1, pp. 1-6.

Ma, L., Lee, C.S. and Goh, D.H.-L. (2014), "Understanding news sharing in social media: an explanation from the diffusion of innovations theory", Online Information Review, Vol. 38 No. 5, pp. 598-615.

Ma, W.W. and Chan, A. (2014), "Knowledge sharing and social media: Altruism, perceived online attachment motivation, and perceived online relationship commitment", Computers in Human Behavior, Vol. 39, pp. 51-58. 
Madhusudhan, M. (2012). "Use of social networking sites by research scholars of the University of Delhi: A study". The International Information \& Library Review, 44(2), 100-113.

Majchrzak, A., Faraj, S., Kane, G. C. \& Azad, B. (2013). "The Contradictory Influence of Social Media Affordances on Online Communal Knowledge Sharing". Journal of ComputerMediated Communication, Vol. 19 No.1, pp. 38-55.

Moqbel, M. (2012). "The effect of the use of social networking sites in the workplace on job performance". Doctor of philosophy, Texas A\&M International University, Laredo, Texas.

Nández, G., \& Borrego, Á. (2013). "Use of social networks for academic purposes: a case study". The electronic library, 31(6), 781-791.

Nassuora, A.B. and Hasan, S. (2010), "Knowledge sharing among academics in instituitions of higher learning", Knowledge Management International Conference, Terengganu, pp. 164-173.

Oh, S. and Syn, S.Y. (2015), "Motivations for sharing information and social support in social media: a comparative analysis of Facebook, Twitter, Delicious, YouTube, and Flickr", Journal of the Association for Information Science and Technology, Vol. 66 No. 10, pp. 2045-2060.

Okazaki, S., Andreu, L. \& Campo, S. (2017). "Knowledge Sharing Among Tourists via Social Media: A Comparison Between Facebook and TripAdvisor". International Journal of Tourism Research, Vol. 19 No.1, pp. 107-119.

Olivera, F. (2000), "Memory systems in organizations: an empirical investigation of mechanisms for knowledge collection, storage and access", Journal of Management Studies, Vol. 37 No. 6, pp. 811-832.

Oostervink, N., Agterberg, M. \& Huysman, M. (2016). "Knowledge Sharing on Enterprise Social Media: Practices to Cope With Institutional Complexity". Journal of Computer-Mediated Communication, Vol. 21 No. 2, pp. 156-176.

Panahi, S. (2014), "Social media and tacit knowledge sharing: physicians' perspectives and experiences", Doctor of Philosophy, Queensland University of Technology, Queensland.

Panahi, S., Watson, J. \& Partridge, H. (2012a). "Potentials of social media for tacit knowledge sharing amongst physicians: preliminary findings". Proceedings of the 23rd Australasian Conference on Information Systems, ACIS 2012. Deakin University, Australia

Panahi, S., Watson, J. and Partridge, H. (2012b), "Social media and tacit knowledge sharing: developing a conceptual model", World Academy of Science, Engineering and Technology, pp. 1095-1102.

Panahi, S., Watson, J. \& Partridge, H. (2013). "Towards tacit knowledge sharing over social web tools". Journal of Knowledge Management, Vol. 17 No. 3, pp. 379-397.

Panahi, S., Watson, J. and Partridge, H. (2016a), "Conceptualising social media support for tacit knowledge sharing: physicians' perspectives and experiences”, Journal of Knowledge Management, Vol. 20 No. 2, pp. 344-363.

Panahi, S., Watson, J. and Partridge, H. (2016b), "Information encountering on social media and tacit knowledge sharing", Journal of Information Science, Vol. 42 No. 4, pp. 539-550.

Papadopoulos, T., Stamati, T. and Nopparuch, P. (2013), "Exploring the determinants of knowledge sharing via employee weblogs", International Journal of Information Management, Vol. 33 No. 1, pp. 133-146.

Petrash, G. (1996), "Dow's journey to a knowledge value management culture”, European Management Journal, Vol. 14 No. 4, pp. 365-373.

Pi, S.-M., Chou, C.-H. \& Liao, H.-L. (2013). "A study of Facebook Groups members' knowledge sharing". Computers in Human Behavior, Vol. 29 No. 5, pp. 1971-1979.

Ramayah, T., Yeap, J.A. and Ignatius, J. (2013), “An empirical inquiry on knowledge sharing among academicians in higher learning institutions", Minerva, Vol. 51 No. 2, pp. 131-154.

Razmerita, L., Kirchner, K. and Nabeth, T. (2014), "Social media in organizations: leveraging personal and collective knowledge processes", Journal of Organizational Computing and Electronic Commerce, Vol. 24 No. 1, pp. 74-93.

Rotter, J. B. (1966). "Generalized expectancies for internal versus external control of reinforcement". Psychological Monographs: General and Applied, Vol. 80 No. 1, pp. 1- 28.

Shoffner, M. F., Newsome, D. W. \& Barrio, C. A. (2005). "Young adolescents' outcome expectations: A qualitative study". Unpublished manuscript. National Science Foundation 
Sohail, M.S. and Daud, S. (2009), "Knowledge sharing in higher education institutions: perspectives from Malaysia", Vine, Vol. 39 No. 2, pp. 125-142.

Srivastava, A., Bartol, K.M. and Locke, E.A. (2006), "Empowering leadership in management teams: Effects on knowledge sharing, efficacy, and performance", Academy of Management Journal, Vol. 49 No. 6, pp. 1239-1251.

Treem, J. W., \& Leonardi, P. M. (2012). "Social media use in organizations: Exploring the affordances of visibility, editability, persistence, and association". Communication yearbook, $36(1), 143-189$.

Van Noorden, R. (2014). "Online collaboration: Scientists and the social network". Nature news, 512(7513), 126-129.

van Winkelen, C. \& McKenzie, J. (2011)."Using social media for knowledge sharing". Van Winkelen \& McKenzie (1 ed), Knowledge works: the handbook of practical ways to identify and solve common organizational problems for better performance., John Wiley \& Sons, United Kingdom, pp. 199 - 215

Veletsianos, G. (2016), Social Media in Academia: Networked Scholars, Routledge, New York, NY.

Veletsianos, G. (2017), "Toward a generalizable understanding of Twitter and social media use across MOOCs: who participates on MOOC hashtags and in what ways?", Journal of Computing in Higher Education, Vol. 29 No. 1, pp. 65-80.

Vuori, V. and Okkonen, J. (2012), "Knowledge sharingmotivational factors of using an intraorganizational social media platform", Journal of Knowledge Management, Vol. 16 No. 4, pp. 592-603.

Yu, Lu, L. C. \& Liu, T. F. (2010a). "Exploring factors that influence knowledge sharing behavior via weblogs". Computers in Human Behavior, Vol. 26 No. 1, pp. 32-41.

Yu, A., Tian, S., Vogel, D. \& Kwok, R. (2010b). "Embedded Social Learning in Online Social Networking". ICIS 2010. available at: http://www.academia.edu/download/41919465/Embedded Social Learning in Onlin e Socia20160202-15521-jtzwxw.pdf (accessed 21 September 2017).

Yuan, Y. C., Zhao, X., Liao, Q. \& Chi, C. (2013). "The use of different information and communication technologies to support knowledge sharing in organizations: From e-mail to micro-blogging". Journal of the American Society for Information Science and Technology, Vol. 64 No. 8, pp. 1659-1670. 


\section{Appendix A: Interview Guide}

\section{General Information}

1- Can you tell me a little bit about your job in the university? What are you doing exactly?

2- How long have you been doing this job?

3- Do you use social media? (if answer yes, go to Q 4; else go to Q 12)

4- What social media platforms do you usually use?

5- Have you used these platforms or any of them for professional purposes in your job such as sharing experience with your colleagues? (If answer yes, go to Q 6, else go to Q 13).

6- Have you used these platforms or any of them to share your research outputs with your colleagues? Could you specify what you have shared?

12- Why do you not use social media?

13- Why do you not use social media for sharing your experience or research outputs specifically? 
Table 1: Types of outcome expectations

\begin{tabular}{|c|c|c|}
\hline Types of Outcomes & $\begin{array}{c}\text { Forms of the Types } \\
\text { of Outcomes }\end{array}$ & Sub-themes \\
\hline \multirow{5}{*}{ Social } & \multirow{4}{*}{ Positive } & Attracting People \\
\hline & & Networking \\
\hline & & Social Impact \\
\hline & & Visibility \\
\hline & Negative & Lack of Trust \\
\hline \multirow{8}{*}{ Personal } & \multirow{5}{*}{ Positive } & Get Help \\
\hline & & Get feedback \\
\hline & & Publicising and Citation \\
\hline & & Keeping up-to-date \\
\hline & & Get Job \\
\hline & \multirow{3}{*}{ Negative } & Distractions \\
\hline & & Privacy concerns \\
\hline & & Time-Consuming \\
\hline
\end{tabular}




1
2
3
4
5
6
7
8
9
10
11
12
13
14
15
16
17
18
19
20
21
22
23
24
25
26
27
28
29
30
31
32
33
34
35
36
37
38
39
40
41
42
43
44
45
46
47
48
49
50
51
52
53
54
55
56
57
58
59
60

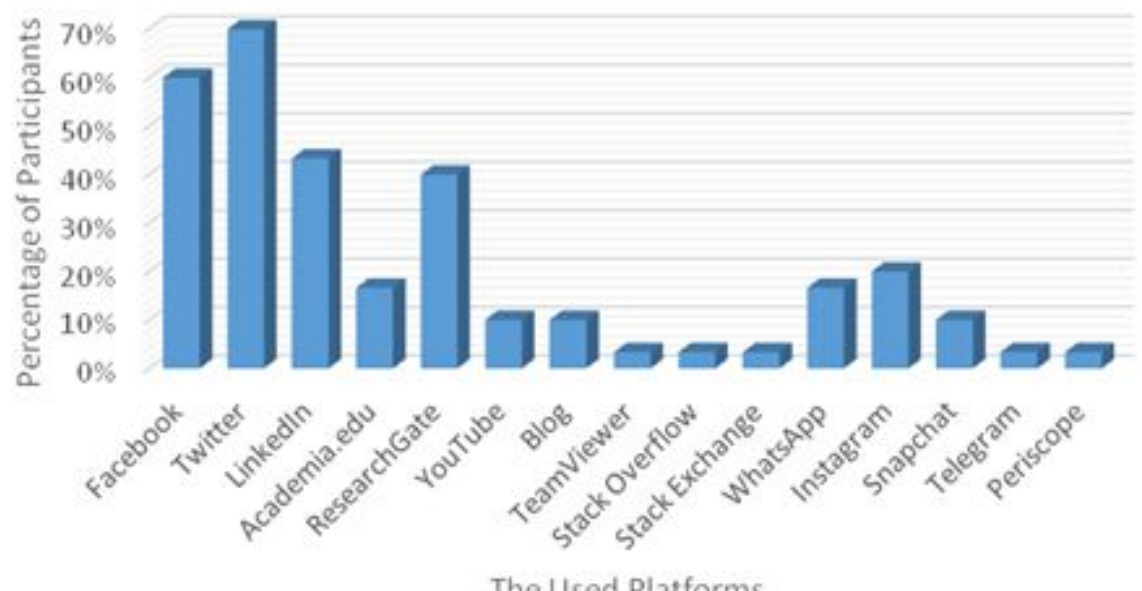

The Used Platforms

Figure 1: The Social Media Platforms Used 